\title{
Effectiveness and drug retention of biologic disease-modifying antirheumatic drugs in Korean patients with late-onset ankylosing spondylitis: Retrospective Cohort Study
}

\section{Se Hee Kim}

Konkuk University Hospital: Konkuk University Medical Center https://orcid.org/0000-0002-9987-7480 Hae-Rim Kim

Konkuk University Medical Center

\section{Sang-Heon Lee}

Konkuk University Medical Center

Kichul Shin

Seoul National University Seoul Metropolitan Government Boramae Medical Center Hyoun-Ah Kim

Ajou University School of Medicine and Graduate School of Medicine Hong Ki Min ( $\square$ alsghdr1921@naver.com )

Konkuk University Hospital: Konkuk University Medical Center https://orcid.org/0000-0003-1147-1046

\section{Research article}

Keywords: ankylosing spondylitis, late-onset, biologics, drug efficacy, drug retention

Posted Date: April 28th, 2021

DOl: https://doi.org/10.21203/rs.3.rs-454104/v1

License: (c) (i) This work is licensed under a Creative Commons Attribution 4.0 International License.

Read Full License 


\section{Abstract}

Background: The clinical data on the biologic disease-modifying antirheumatic drug (bDMARD) use in late-onset ankylosing spondylitis (LOAS) is limited. Thus, this study aimed to evaluate the drug efficacy and retention rate of bDMARDs in LOAS and compare it to young-onset ankylosing spondylitis (YOAS).

Methods: Data of patients with AS receiving bDMARDs were extracted from the Korean College of Rheumatology Biologics and Targeted Therapy registry. Patients whose age of onset was $>50$ years and $<50$ years were classified as having LOAS and YOAS, respectively. Their baseline characteristics and disease-associated parameters were evaluated. Drug efficacy (Ankylosing Spondylitis Disease Activity Score [ASDAS]-clinically important improvement [CII], ASDAS-major improvement [MI], Assessment of SpondyloArthritis International Society [ASAS] 20, and ASAS 40) at 1-year follow-up and drug retention rates were assessed.

Results: A total of 1708 patients (comprising 1472 patients with YOAS and 236 patients with LOAS) were included in this analysis. The LOAS group had a lower prevalence among males, lower HLA-B27 positivity and a higher prevalence of peripheral arthritis. Patients with LOAS were more likely to have higher disease-associated parameters (inflammatory reactants, patient global assessment, ASDAS-erythrocyte sedimentation rate, and ASDAS-C-reactive protein). LOAS was negatively associated with achieving ASDAS-CII, ASAS 20, and ASAS 40. The drug retention rate was lower in LOAS; however, the propensity score-matched and covariate-adjusted hazard ratios for bDMARD discontinuation were comparable to YOAS. There were no differences in the drug retention rates based on the type of bDMARD used in LOAS.

Conclusion: Inferior clinical efficacy and drug retention rates were found in patients with LOAS receiving bDMARDs using real-world nationwide data. There were no differences among each bDMARD type.

\section{Key Messages}

1. Drug efficacy of bDMARDs in late-onset AS was lower than in young-onset AS.

2. Drug retention rate of bDMARDs in late-onset AS was lower than in young-onset AS

3. However, being LOAS was not an independent predictor for bDMARDs discontinuation.

\section{Background}

Ankylosing spondylitis (AS) is a prototype of axial spondyloarthritis (axSpA), which is a chronic and systemic inflammatory arthritis of the axial skeleton, associated with radiographic changes [1]. Symptoms usually begin before the age of 30 years, and patients are often diagnosed before the age of 40 years. Patients with human leukocyte antigen (HLA)-B27 are more likely to develop axSpA [2].

Although the Assessment of SpondyloArthritis International Society (ASAS) classification has criteria for inflammatory back pain starting at $<45$ years of age [3], some patients are diagnosed at an older age due 
to late symptom onset [4]. The issue of patients with late-onset AS (LOAS) raises concerns for revising the definition of inflammatory back pain. Unlike young-onset AS (YOAS), LOAS is less likely to be associated with HLA-B27 positivity, inflammatory back pain, alternating buttock pain, radiographic sacroiliitis, and hip involvement [4-8]. ). More frequently observed features in LOAS are cervical spine involvement and peripheral arthritis as first manifestations, dactylitis, articular synovitis on power Doppler ultrasound, tenosynovitis or peritendinitis of digit and wrist flexors, and enthesitis of digital collateral ligaments. Additionally, LOAS is associated with female sex, higher levels of acute-phase reactants, nail involvement, and psoriasis $[4-6,9]$.

AS is usually an early onset disease and is rarely diagnosed in older people. Late-onset disease (symptom onset $>50$ years of age) can mimic other rheumatic diseases. This results in a delayed diagnosis of axSpA. Physicians often misdiagnose LOAS as rheumatoid arthritis, polymyalgia rheumatica, and osteoarthritis, as these are more common in the middle age group [10]. The current entry criterion for inflammatory back pain onset $<45$ years in axSpA makes diagnosing LOAS challenging and increases the chances of delayed diagnoses and misdiagnoses.

Biologic disease-modifying antirheumatic drugs (bDMARDs) are emerging as promising treatments for AS. Current ASAS/European League Against Rheumatism (EULAR) [11] and American College of Rheumatology/Spondylitis Association of America/Spondyloarthritis Research and Treatment Network [12] guidelines recommend their use in patients who do not respond to non-steroidal anti-inflammatory drugs (NSAIDs). The demand for bDMARD prescription would increase if it was shown to have a higher retention rate. However, there is insufficient data on the long-term drug efficacy and retention rate in patients with LOAS [10].

This study aimed to identify the efficacy and retention rate of bDMARDs in patients with AS $>50$ years of age (LOAS) and compare them with the YOAS group in the Korean population. In addition, we also aimed to evaluate the impact of LOAS on drug efficacy and retention rate.

\section{Methods}

\section{Patient population and data collection}

Data were extracted from the Korean College of Rheumatology Biologics and Targeted Therapy (KOBIO) Registry. This is a nationwide prospective cohort that collects data on adverse events and efficacy of biologic and targeted synthetic DMARDs (tsDMARDs) in patients with AS, rheumatoid arthritis, and psoriatic arthritis [13]. A total of 58 tertiary hospital rheumatologic clinics participate in this registry that has been established in 2012. The inclusion criteria for this study were age $>18$ years; patients fulfilling the 1984 modified New York (mNY) criteria for AS [14]; and patients who were initiated on, switched to, or re-started on bDMARDs. Patients with non-radiographic axSpA are not enrolled in the KOBIO registry. The patients with AS were divided into LOAS (symptom onset at age $>50$ years) and YOAS (symptom onset at age $<50$ years) as per previous studies $[4,10,15]$. Data of patients from the beginning of the registry until October 2020 were included in this study and 2023 patients were initially screened. Informed 
consent was obtained from all participants before enrolment at each centre. This study was conducted according to the principles of the Declaration of Helsinki and was approved by the Institutional Review Board of Konkuk University Medical Centre (KUMC 2020-12-001).

\section{Data analysis}

Baseline demographics assessed the features of AS and the laboratory information according to the ASAS classification criteria for axSpA, which are inflammatory back pain, arthritis, enthesitis, uveitis, dactylitis, psoriasis, Crohn's colitis, good response to NSAIDs, family history of SpA, HLA-B27 positivity, and elevated C-reactive protein (CRP). Disease-associated parameters such as Bath Ankylosing Spondylitis Disease Activity Index (BASDAI), Patient's Global Assessment (PGA), Bath Ankylosing Spondylitis Functional Index (BASFI), Ankylosing Spondylitis Disease Activity Score (ASDAS)-Erythrocyte Sediment Rate (ESR), and ASDAS-CRP were calculated. They were assessed the 1-year follow-up and changes from baseline were used to assess drug efficacy. The total bDMARD retention rate was also evaluated. The ASDAS criteria for improvement were $\geq 1.1$ units for clinically important improvement (CII) and $\geq 2.0$ units for major improvement (MI) [16]. The treatment response was assessed using ASAS 20 and ASAS 40. ASAS 20 was defined as an improvement of least $20 \%$ and at least 1 unit in 3 out of 4 domains (PGA, pain assessment, BASFI, and inflammation) on a scale of 0 to 10 , without worsening of $20 \%$ and at least 1 unit in the remaining domain. ASAS 40 was defined as an improvement of at least $40 \%$ and at least 2 units in 3 domains on a scale of 0 to 10, without worsening of $20 \%$ and at least 1 unit in the remaining domain [17]. All results of LOAS were compared with those of YOAS.

\section{Statistical analysis}

Continuous variables were initially assessed using the Kolmogorov-Smirnov test to define the normality of distribution. Then Student's t-test and Mann-Whitney $U$ test were used to compare the continuous variables and present them as mean ( $\pm S D$ ) or median (IQR). Categorical variables were presented as frequencies and percentages. The $\chi^{2}$-test (Mantel-Haenszel $\chi^{2}$-test for more than $2 \times 2$ categorical data) or Fisher's exact test were used for comparing categorical variables. Logistic regression identified predictors of ASDAS-CII, ASDAS-MI, ASAS 20, and ASAS 40 achievement at 1-year follow-up, and all known covariates potentially influencing drug efficacy were adjusted for. These include age, sex, HLA-B27 positivity, ASDAS, BASFI, presence of peripheral arthritis, history of bDMARD use (a dichotomous variable; bDMARDs naïve versus bDMARDs exposed), type of bDMARD, and smoking status [18]. The results of the logistic regression analysis were presented as odds ratio (OR) with 95\% confidence intervals $(\mathrm{Cl})$. Drug retention was analysed using Kaplan-Meier plots and the log-rank test. Cox regression analysis was used to determine the associated variates of bDMARD discontinuation. Propensity score (PS) matching was performed as a 1:1 ratio via imputing variables known to influence drug response. These variables include sex, body mass index (BMI), smoking status, HLA-B27 positivity, ASDAS, BASFI, peripheral arthritis, and history of bDMARD use. A value of $p<0.05$ was considered statistically significant. All analyses were performed using SPSS ver. 25 (version 25.0 for Windows, Chicago, IL, USA). 


\section{Results}

\section{Baseline characteristics}

A total of 1708 patients with 1-year follow-up data were included in this study, 1472 of whom belonged to the YOAS group and 236 to the LOAS group. The median age was 29.0 years (22.1-37.1 years) and 57.0 years (IQR 54.0-61.1 years) for the YOAS and LOAS groups, respectively. Male predominance was lower in the LOAS group than in the YOAS group (144 patients [61.0\%] vs $1170[79.5 \%], p<0.001$ ). More patients in the LOAS group had never smoked (140 patients [59.3\%] vs 719 patients [48.8\%], $p<0.001$ ). Patients with LOAS were less likely to be HLA-B27 positive and more likely to have peripheral arthritis. They were also more likely to have higher ESR, CRP, PGA, and ASDAS-ESR/CRP than those with YOAS (Table 1). 
Table 1 Baseline characteristics of young and late onset ankylosing spondylitis patients at the time of enrollment

\begin{tabular}{|c|c|c|c|}
\hline $\begin{array}{l}\text { Variable } \\
\mathrm{N}(\%) \text { or median with IQR }\end{array}$ & $\begin{array}{c}\text { YOAS } \\
(\mathrm{N}=1472)\end{array}$ & $\begin{array}{c}\text { LOAS } \\
(\mathrm{N}=236)\end{array}$ & $p$-value ${ }^{\dagger}$ \\
\hline Age (year-old) & $29.0[22.1 ; 37.1]$ & $57.0[54.0 ; 61.1]$ & $<0.001$ \\
\hline Symptom duration (months) & $11.6[30.5 ; 37.1]$ & $11.4[32.2 ; 60.1]$ & 0.092 \\
\hline Male & $1170(79.5 \%)$ & $144(61.0 \%)$ & $<0.001$ \\
\hline BMI & $23.3[21.1 ; 25.7]$ & $23.6[21.4 ; 25.6]$ & 0.456 \\
\hline Smoking & & & $<0.001$ \\
\hline Ex-smoker & $289(19.6 \%)$ & $62(26.3 \%)$ & \\
\hline Current smoker & $464(31.5 \%)$ & $34(14.4 \%)$ & \\
\hline Never & $719(48.8 \%)$ & $140(59.3 \%)$ & \\
\hline Biologic naïve & $1127(76.6 \%)$ & $207(87.7 \%)$ & $<0.001$ \\
\hline Right sacroiliitis grade & $2.61[2.56 ; 2.67]$ & $2.59[2.46 ; 2.72]$ & 0.768 \\
\hline Left sacroiliitis grade & $2.6[2.55 ; 2.65]$ & $2.56[2.43 ; 2.69]$ & 0.577 \\
\hline Swelling joint count & $0.53[0.44 ; 0.63]$ & $1.59[1.53 ; 1.65]$ & 0.026 \\
\hline Tender joint count & $0.53[0.44 ; 0.63]$ & $1.11[0.61 ; 1.61]$ & 0.001 \\
\hline \multicolumn{4}{|c|}{ Features of ASAS Classification Criteria of axSpA } \\
\hline $\begin{array}{l}\text { Acute Inflammation on MRI } \\
\text { highly suggestive of sacroiliitis } \\
\text { associated with SpA }\end{array}$ & $332(22.6 \%)$ & $61(25.8 \%)$ & 0.536 \\
\hline $\begin{array}{l}\text { Definite radiographic sacroiliitis } \\
\text { according to modified NY criteria }\end{array}$ & $1320(89.7 \%)$ & $214(90.7 \%)$ & 0.721 \\
\hline Inflammatory back pain & $1250(84.9 \%)$ & $192(81.4 \%)$ & 0.209 \\
\hline Arthritis & $392(26.6 \%)$ & $95(40.3 \%)$ & $<0.001$ \\
\hline Enthesitis & $231(15.7 \%)$ & $39(16.5 \%)$ & 0.847 \\
\hline Uveitis & $127(8.6 \%)$ & $26(11.0 \%)$ & 0.487 \\
\hline Dactylitis & $21(1.4 \%)$ & $6(2.5 \%)$ & 0.414 \\
\hline Psoriasis & $38(2.6 \%)$ & $8(3.4 \%)$ & 0.694 \\
\hline Crohn's colitis & $8(0.5 \%)$ & $0(0.0 \%)$ & 0.518 \\
\hline Good response to NSAIDs & $509(34.6 \%)$ & $86(36.4 \%)$ & 0.694 \\
\hline Family history for SpA & $164(11.1 \%)$ & $27(11.4 \%)$ & 0.486 \\
\hline HLA-B27 & $1244(84.5 \%)$ & $175(74.2 \%)$ & $<0.001$ \\
\hline Elevated CRP & $1005(68.3 \%)$ & $163(69.1 \%)$ & 0.464 \\
\hline \multicolumn{4}{|l|}{ Comorbidity } \\
\hline Hypertension & $164(11.1 \%)$ & $94(39.8 \%)$ & $<0.001$ \\
\hline Ischemic Heart Disease & $15(1.0 \%)$ & $7(3.0 \%)$ & 0.002 \\
\hline Hyperlipidemia & $185(12.6 \%)$ & $47(19.9 \%)$ & 0.009 \\
\hline Congestive Heart failure & $3(0.2 \%)$ & $0(0.0 \%)$ & 0.076 \\
\hline Arrhythmia & $11(0.7 \%)$ & $5(2.1 \%)$ & 0.118 \\
\hline Peripheral vascular disorder & $0(0 \%)$ & $0(0 \%)$ & 1.000 \\
\hline Stroke & $2(0.1 \%)$ & $0(0.0 \%)$ & 1.000 \\
\hline Osteoporosis & $38(2.6 \%)$ & $29(12.3 \%)$ & $<0.001$ \\
\hline Diabetes without complication & $36(2.4 \%)$ & $30(12.7 \%)$ & $<0.001$ \\
\hline Diabetes with complication & $7(0.5 \%)$ & $2(0.8 \%)$ & 0.804 \\
\hline Hyperthyroidism & $5(0.3 \%)$ & $2(0.8 \%)$ & 0.559 \\
\hline Hypothyroidism & $7(0.5 \%)$ & $9(3.8 \%)$ & $<0.001$ \\
\hline Renal failure & $6(0.4 \%)$ & $6(2.5 \%)$ & 0.001 \\
\hline Peptic ulcer & $28(1.9 \%)$ & $5(2.1 \%)$ & 1.000 \\
\hline Liver disease & $24(1.6 \%)$ & $3(1.3 \%)$ & 0.897 \\
\hline Tuberculosis & $4(0.3 \%)$ & $0(0.0 \%)$ & 0.939 \\
\hline Anemia & $254(17.3 \%)$ & $110(46.6 \%)$ & $<0.001$ \\
\hline \multicolumn{4}{|l|}{ Disease associated parameters } \\
\hline BASDAI & $6.1[4.8 ; 7.3]$ & $6.4[5.0 ; 7.7]$ & 0.083 \\
\hline PGA & $6.3[6.2 ; 6.4]$ & $6.6[6.3 ; 6.9]$ & 0.028 \\
\hline ESR & $27.5[13.0 ; 51.0]$ & $47.5[20.0 ; 76.0]$ & $<0.001$ \\
\hline CRP & $1.0[0.3 ; 2.5]$ & $1.7[0.4 ; 4.0]$ & 0.001 \\
\hline ASDAS-ESR & $3.6[2.9 ; 4.3]$ & $4.1[3.3 ; 4.9]$ & $<0.001$ \\
\hline ASDAS-CRP & $3.6[2.9 ; 4.3]$ & $3.8[3.0 ; 4.7]$ & 0.002 \\
\hline BASFI & $2.8[1.0 ; 5.2]$ & $3.7[1.8 ; 6.1]$ & 0.078 \\
\hline
\end{tabular}

+Comparing each group with Kruskal-Wallis test or $\chi^{2}$ test.

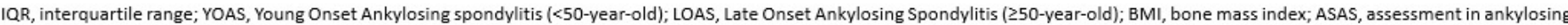

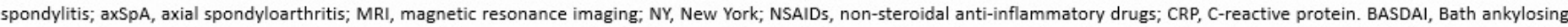

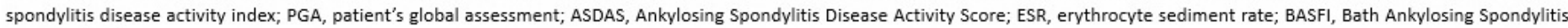
Functional Index

\section{Drug efficacy at 1-year follow-up}

ASDAS-CII, ASDAS-MI, ASAS 20, and ASAS 40 achievement rates at 1-year follow-up for every type of bDMARD are summarised in Table 2. Overall, ASDAS-CII and ASDAS-MI were not different between the two groups, whereas ASAS 20 and ASAS 40 were higher in the YOAS group than in the LOAS group. In the subgroup analysis of specific bDMARDs, there was no significant difference in terms of ASDAS-CII, ASDAS-MI, ASAS 20, and ASAS 40 between the two groups. 
Table 2 ASDAS-CII and ASDAS-MI in each TNF- $\alpha$ inhibitors

\begin{tabular}{llccc}
\hline TNF- $\alpha$ inhibitor & & YOAS & LOAS & $p$-valuet \\
\hline \multirow{4}{*}{ Overall, $\mathrm{n}(\%)$} & ASDAS-CII & $1046(71.9 \%)$ & $157(66.5 \%)$ & 0.104 \\
& ASDAS-MI & $327(22.5 \%)$ & $47(19.9 \%)$ & 0.424 \\
& ASAS 20 & $819(58.9 \%)$ & $106(46.7 \%)$ & 0.001 \\
& ASAS 40 & $606(43.6 \%)$ & $81(35.7 \%)$ & 0.031 \\
\hline \multirow{5}{*}{ Etanercept, $\mathrm{n}(\%)$} & ASDAS-CII & $153(69.9 \%)$ & $27(73.0 \%)$ & 0.851 \\
& ASDAS-MI & $54(24.7 \%)$ & $10(27.0 \%)$ & 0.918 \\
& ASAS 20 & $113(51.6 \%)$ & $15(40.5 \%)$ & 0.437 \\
& ASAS 40 & $78(35.6 \%)$ & $13(35.1 \%)$ & 0.998 \\
\hline \multirow{5}{*}{ Infliximab, $\mathrm{n}(\%)$} & ASDAS-CII & $221(68.8 \%)$ & $41(62.1 \%)$ & 0.366 \\
& ASDAS-MI & $66(20.6 \%)$ & $10(15.2 \%)$ & 0.427 \\
& ASAS 20 & $168(52.5 \%)$ & $31(47.0 \%)$ & 0.095 \\
& ASAS 40 & $130(40.6 \%)$ & $22(33.3 \%)$ & 0.074 \\
\hline \multirow{5}{*}{ Adalimumab, $\mathrm{n}(\%)$} & ASDAS-CII & $423(72.8 \%)$ & $64(68.1 \%)$ & 0.401 \\
& ASDAS-MI & $127(21.9 \%)$ & $15(16.0 \%)$ & 0.238 \\
& ASAS 20 & $325(56.1 \%)$ & $43(45.7 \%)$ & 0.171 \\
& ASAS 40 & $246(42.5 \%)$ & $33(35.1 \%)$ & 0.388 \\
\hline \multirow{5}{*}{ Golimumab, $\mathrm{n}(\%)$} & ASDAS-CII & $249(74.8 \%)$ & $25(64.1 \%)$ & 0.219 \\
& ASDAS-MI & $80(24.0 \%)$ & $12(30.8 \%)$ & 0.474 \\
& ASAS 20 & $213(63.4 \%)$ & $17(43.6 \%)$ & 0.055 \\
& ASAS 40 & $152(45.2 \%)$ & $13(33.3 \%)$ & 0.356 \\
\hline & ASDAS-CII & 0.317 & 0.689 & \\
& ASDAS-MI & 0.602 & 0.116 & \\
& ASAS 20 & 0.076 & 0.684 & \\
\hline & ASAS 40 & 0.446 & 0.688 & \\
& & & &
\end{tabular}

† Comparing YOAS and LOAS with $\chi^{2}$ test

¥ Comparing between subtypes of TNF- $\alpha$ inhibitors with Mantel-Haenszel $\chi^{2}$ test

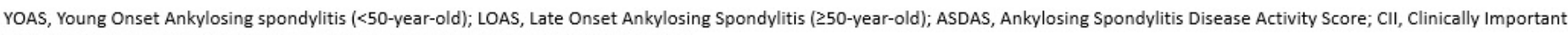
Improvement; MI, Major Improvement, ASAS, Assessment of Ankylosing Spondylitis

The logistic regression analysis showed that LOAS, female sex, bDMARD naiveness, and secukinumab were negatively associated with achieving ASDAS-CII. ASDAS-ESR was positively associated with achieving ASDAS-CII (OR = 2.882) (Table 3). Female sex and BASFI score were positively associated with achieving ASDAS-MI (Supplementary Table S1). LOAS, female sex, BMI $<18.5 \mathrm{~kg} / \mathrm{m}^{2}$, ex-smoker and current smoker statuses, HLA-B27 negativity, and bDMARD naiveness were negatively associated with ASAS 20. The same variates (except for smoking status and BMI) were also negatively associated with ASAS 40. ASDAS-ESR and BASFI were positively associated with ASAS 20 and ASAS 40 (Supplementary Tables S2 \& S3). 
Table 3. Logistic regression of ASDAS-CII

\begin{tabular}{|c|c|c|c|c|}
\hline Method & Variate & Odds ratio & $95 \% \mathrm{Cl}$ & $p$-value \\
\hline $\begin{array}{l}\text { Propensity score- } \\
\text { based }\end{array}$ & LOAS (compared to YOAS) & 0.507 & $0.335-0.770$ & 0.001 \\
\hline \multirow[t]{22}{*}{ Covariate adjustment } & LOAS (compared to YOAS) & 0.497 & $0.342-0.723$ & $<0.001$ \\
\hline & Female (compared to male) & 0.619 & $0.440-0.870$ & 0.006 \\
\hline & BMI $\left(\mathrm{kg} / \mathrm{m}^{2}\right)$ & & & \\
\hline & $<18.5$ & 0.737 & $0.389-1.393$ & 0.347 \\
\hline & $18.5-22.9$ & $\begin{array}{l}1.000 \\
\text { (Reference) }\end{array}$ & & \\
\hline & $23.0-24.9$ & 0.933 & $0.674-1.291$ & 0.675 \\
\hline & $\geq 25.0$ & 0.906 & $0.671-1.223$ & 0.520 \\
\hline & Smoking status & & & \\
\hline & Non smoker & $\begin{array}{l}1.000 \\
\text { (Reference) }\end{array}$ & & \\
\hline & Ex-smoker & 0.814 & $0.571-1.161$ & 0.256 \\
\hline & Current smoker & 0.765 & $0.560-1.045$ & 0.093 \\
\hline & HLA B27 negative & 0.688 & $0.465-1.018$ & 0.062 \\
\hline & ASDAS & 2.882 & $2.460-3.377$ & $<0.001$ \\
\hline & BASFI score & 1.005 & $0.950-1.063$ & 0.855 \\
\hline & Peripheral arthritis, yes vs. no & 0.812 & $0.600-1.099$ & 0.177 \\
\hline & $\begin{array}{l}\text { Biologics naïve (compared to } \\
\text { previous TNFi exposure group) }\end{array}$ & 0.499 & $0.373-0.669$ & $<0.001$ \\
\hline & Biologics type & & & \\
\hline & Etanercept & $\begin{array}{l}1.000 \\
\text { (Reference) }\end{array}$ & & \\
\hline & Infliximab & 0.837 & $0.557-1.259$ & 0.393 \\
\hline & Adalimumab & 1.175 & $0.807-1.711$ & 0.401 \\
\hline & Golimumab & 1.029 & $0.675-1.568$ & 0.894 \\
\hline & Secukinumab & 0.240 & $0.064-0.896$ & 0.034 \\
\hline
\end{tabular}

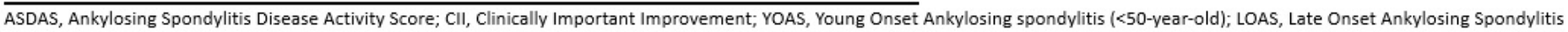

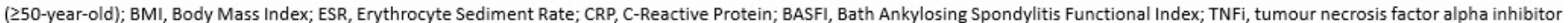

AS-associated parameters were evaluated using BASDAI, PGA, ESR, CRP, ASDAS-ESR/CRP, and BASFI. The overall scores of disease activity were higher in the LOAS group than in the YOAS group at baseline and 1-year follow-up except for ESR. BASDAI was associated with a lesser decline in the LOAS group than the YOAS group, whereas ESR and CRP were associated with a greater decline in LOAS group. The changes of PGA, ASDAS-ESR/CRP, and BASFI between LOAS and YOAS were not significantly different (Table 4).

Table 4. Change of activity at initial enrollment and 1 year follow-up

\begin{tabular}{|c|c|c|c|}
\hline & $\begin{array}{c}\text { YOAS } \\
(\mathrm{N}=1472)\end{array}$ & $\begin{array}{c}\text { LOAS } \\
(n=236)\end{array}$ & $p$-valuet \\
\hline$\Delta \mathrm{ESR}$ & $16.0[2.5 ; 38.0]$ & $22.0[4.0 ; 54.0]$ & 0.004 \\
\hline$\triangle C R P$ & $0.7[0.0 ; 2.0]$ & $1.2[0.0 ; 3.5]$ & 0.005 \\
\hline$\triangle \mathrm{BASDAI}$ & $3.6[1.7 ; 5.2]$ & $3.2[0.9 ; 4.9]$ & 0.007 \\
\hline$\triangle \mathrm{PGA}$ & $3.0[1.0 ; 5.0]$ & $3.0[1.0 ; 5.0]$ & 0.059 \\
\hline$\triangle$ ASDAS-ESR & $1.9[1.0 ; 2.8]$ & $1.6[0.8 ; 2.8]$ & 0.148 \\
\hline$\triangle$ ASDAS-CRP & $2.0[1.0 ; 2.9]$ & $1.9[0.8 ; 3.0]$ & 0.593 \\
\hline$\triangle \mathrm{BASFI}$ & $1.3[0.1 ; 3.5]$ & $1.6[0.1 ; 3.8]$ & 0.494 \\
\hline
\end{tabular}

+Comparing YOAS and LOAS with Kruskal-Wallis test.

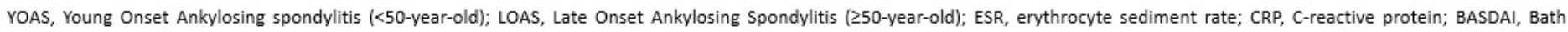

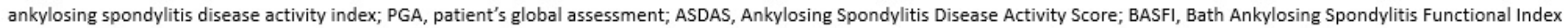


The overall bDMARD retention rates of YOAS and LOAS with median durations of 13.5 months and 11.0 months, respectively are summarised in Figure 1A. In the LOAS group, the drug retention rate was significantly lower than YOAS (Log-rank test $p=0.003$ ). The drug retention rate of LOAS at 1-year followup was $72.5 \%, 57.9 \%$ at 3-year, $48.0 \%$ at 5-year, and $36 \%$ at 7-year follow-up. In YOAS, the drug retention rate at 1 -year follow-up was $81.2 \%$, and the rates of every 2 years were $67.5 \%, 57.7 \%$, and $46.1 \%$, consecutively. Among patients with LOAS (Figure 1B), adalimumab continuously had the highest and etanercept had the lowest drug retention rates without any significant differences (adalimumab vs golimumab, Log-rank test $p=0.895$; adalimumab vs infliximab, Log-rank test $p=0.621$; adalimumab vs etanercept, Log-rank test $p=0.104$ ). In the YOAS group (Figure 1C), golimumab consistently had the highest drug retention rate during the 7 years (golimumab vs etanercept and infliximab, Log-rank test $p<$ 0.001; golimumab vs adalimumab, Log-rank test $p=0.05$ ). The lowest retention rates were at the 3-year follow-up for secukinumab, 4- to 7-year follow-up for infliximab, without significant differences with other bDMARDs. The most common reasons for discontinuation were inefficacy followed by adverse events in both groups. In the LOAS group, etanercept demonstrated the highest inefficacy (25.0\%) and remission (8.3\%) while infliximab had the highest rate of adverse events (16.9\%). In the YOAS group, infliximab had the highest inefficiency (15.4\%) and etanercept had the highest rate of adverse events $(12.4 \%)$

\section{(Supplementary Table S4).}

\section{Predictors of bDMARD discontinuation}

In the Cox regression analysis of drug discontinuation, LOAS was not significant in the PS-matched or the covariate-adjusted results $(\mathrm{HR}=1.229 ; 95 \% \mathrm{Cl}: 0.931-1.622$ and $\mathrm{HR}=1.184 ; 95 \% \mathrm{Cl}: 0.934-1.501$, respectively). The HR for bDMARD discontinuation was 1.291 for female sex (95\% $\mathrm{Cl}$ : 1.030-1.617), 1.381 for current smokers (95\% Cl: 1.122-1.700), 1.473 for HLA-B27 negativity (95\% Cl: 1.155-1.878), 0.719 for adalimumab ( $95 \% \mathrm{Cl}: 0.567-0.9110)$, and 0.570 for golimumab ( $95 \% \mathrm{Cl}: 0.433-0.751)$ [in reference to etanercept]. (Table 5) 
Table 5 Multivariate Cox regression analysis of bDMARDs discontinuation in patients of ankylosing spondylitis

\begin{tabular}{|c|c|c|c|c|}
\hline Method & Variate & Hazard ratio & $95 \% \mathrm{Cl}$ & $p$-value \\
\hline $\begin{array}{l}\text { Propensity } \\
\text { score-based }\end{array}$ & LOAS (compared to YOAS) & 1.229 & $0.931-1.622$ & 0.146 \\
\hline \multirow{22}{*}{$\begin{array}{l}\text { Covariate } \\
\text { adjustment }\end{array}$} & LOAS (compared to YOAS) & 1.184 & $0.934-1.501$ & 0.162 \\
\hline & Female (compared to male) & 1.291 & $1.030-1.617$ & 0.027 \\
\hline & $\mathrm{BMI}\left(\mathrm{kg} / \mathrm{m}^{2}\right)$ & & & \\
\hline & $<18.5$ & 1.263 & $0.857-1.861$ & 0.239 \\
\hline & $18.5-22.9$ & $\begin{array}{l}1.000 \\
\text { (Reference) }\end{array}$ & & \\
\hline & $23.0-24.9$ & 0.997 & $0.803-1.236$ & 0.975 \\
\hline & $\geq 25.0$ & 1.104 & $0.908-1.344$ & 0.320 \\
\hline & Smoking status & 1.084 & $0.496-2.367$ & 0.840 \\
\hline & Non smoker & $\begin{array}{l}1.000 \\
\text { (Reference) }\end{array}$ & & \\
\hline & Ex-smoker & 1.116 & $0.882-1.413$ & 0.361 \\
\hline & Current smoker & 1.381 & $1.122-1.700$ & 0.002 \\
\hline & HLA B27 negative & 1.473 & $1.155-1.878$ & 0.002 \\
\hline & ASDAS & 0.945 & $0.864-1.034$ & 0.216 \\
\hline & BASFI score & 1.000 & $0.965-1.036$ & 0.996 \\
\hline & Peripheral arthritis, yes vs. no & 1.178 & $0.979-1.417$ & 0.082 \\
\hline & $\begin{array}{l}\text { Biologics naive (compared to previous } \\
\text { TNFi exposure group) }\end{array}$ & 0.959 & $0.784-1.172$ & 0.679 \\
\hline & Biologics type & & & \\
\hline & Etanercept & $\begin{array}{l}1.000 \\
\text { (Reference) }\end{array}$ & & \\
\hline & Infliximab & 0.995 & $0.775-1.277$ & 0.969 \\
\hline & Adalimumab & 0.719 & $0.567-0.911$ & 0.006 \\
\hline & Golimumab & 0.570 & $0.433-0.751$ & $<0.001$ \\
\hline & Secukinumab & 0.595 & $0.185-1.917$ & 0.385 \\
\hline
\end{tabular}

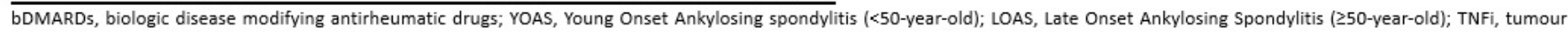
necrosis factor alpha inhibitor; BMI, body mass index; ASDAS, Ankylosing Spondylitis Disease Activity Score; BASFI, Bath Ankylosing Spondylitis Functional Index.

\section{Discussion}

In this study, the efficacy and retention of bDMARDs were examined in patients with LOAS for the first time using a large nationwide registry. Patients with LOAS had a higher prevalence of peripheral arthritis and were less likely to be male or HLA-B27 positive. A lesser decline in BASDAI was observed, in comparison to a greater decline in ESR and CRP in patients with LOAS at the 1-year follow-up compared to those with YOAS. LOAS was negatively associated with achieving ASDAS-CII, ASAS 20, and ASAS 40. The overall drug retention rate was lower in LOAS, without any differences based on bDMARD type. There was no association between LOAS and bDMARD discontinuation.

The use of bDMARDs in older patients with AS is usually associated with poor drug response. In one meta-analysis, older age was negatively associated with achieving BASDAI 50 at the 12-week and 24week follow-up ( $\mathrm{OR}=0.91,95 \% \mathrm{Cl}$ : $0.84-0.99$ and $\mathrm{OR}=0.98,95 \% \mathrm{Cl}: 0.97-0.99$, respectively) [19]. The difference between previous studies and ours is that we demonstrated whether LOAS could impact clinical response and bDMARD retention. Most of the baseline characteristics of LOAS in our study were consistent with those of previous reports $[6,15]$. In our study, LOAS had higher a prevalence of female sex, peripheral arthritis, ESR, and CRP and a lower prevalence of HLA-B27 positivity compared to YOAS. Moreover, disease-associated parameters of PGA and ASDAS-ESR/CRP were higher in LOAS. Inflammatory back pain was not significantly different between YOAS and LOAS. Several of our findings were different from other reports. Skare et al. found that among those with LOAS, there was a lower prevalence of inflammatory low back pain and uveitis, higher prevalence of dactylitis and psoriasis, and comparable CRP levels compared to that of patients with YOAS [6]. Karaarslan et al. showed that 
peripheral arthritis was equivalent between LOAS and YOAS [7]. Endo et al. found that LOAS was less likely to be associated with inflammatory back pain and more likely to be associated with dactylitis. It is important to note that they chose the age of 57 years as the differentiating point between YOAS and LOAS [5]. These variations may be due to inclusion criteria differences as our study only enrolled bDMARDs users. Other factors such as ethnic background and symptom duration prior to diagnosis may have also contributed to these differences. Our study enrolled 236 patients with LOAS, which is much higher compared to other studies. Since LOAS has several different characteristics than YOAS, it should be considered as a unique subgroup of patients with AS.

Therapeutic options for LOAS are based on recommendations from the management of younger patients $[11,12,15]$. Considering the comorbidities are associated with older age, such as peptic ulcer and cardiovascular disease, physicians are often reluctant to prescribe effective drugs such as NSAIDs and TNF-a inhibitors to patients with LOAS. TNF-a inhibitor use in elderly patients with rheumatoid arthritis has shown lower efficacy and increased risk of tuberculosis reactivation, serious infections, and skin cancer [20] Nonetheless, as far as treating AS, they have shown high efficacy and safety according to the ASAS/EULAR [21] Moreover, secukinumab has been emerging as a highly effective remedy in these patients [22, 23]. Since bDMARDs have been proven efficacious and safe [22], the demand for this treatment has been increasing. It is important to note that there are mixed results regarding the type of bDMARDs depending on the time of disease onset. Etanercept was found to be well-tolerated and safe in elderly patients with AS $[24,25]$, whereas the same demographic were more likely to discontinue infliximab and develop severe pyogenic infections [26, 27].

In our study, ASDAS-CII and ASDAS-MI for overall bDMARDs were comparable between LOAS and YOAS; however, ASAS 20 and ASAS 40 were significantly more likely to be achieved in YOAS. In the subgroup analyses according to each bDMARD, LOAS and YOAS were comparable. In the multivariate logistic regression analysis, we demonstrated that bDMARD use in patients with LOAS patients was negatively associated with achieving clinical response. In addition, objective parameters such as ESR and CRP were associated with a greater decline in LOAS whereas BASDAl, a subjective patient grading score, was associated with a lesser decline. Arends et al. reported that the predictors of achieving clinical response to TNF-a inhibitors were increased acute-phase reactants, higher disease activity, higher functional status, younger age, and HLA-B27 positivity [28]. Rusman et al. reported that female sex was associated with a higher disease activity score, lower quality of life score, and lower response to TNF inhibitors [29]. Several previous studies have found that male sex is a predictor for clinical response and drug retention [30-32] despite having more severe disease and radiologic damage [29]. It is possible that the clinical response of LOAS could be affected by higher prevalence of female sex or higher level of inflammatory reactant. Furthermore, similar to previous studies [24-26], the drug retention rate was lower in the LOAS group than in the YOAS group. However, in the co-variate adjusted and PS-matched results of the Cox regression analysis, LOAS was not significantly associated with drug discontinuation. Although LOAS was negatively associated with achieving clinical efficacy at the 1-year follow- up and had a lower drug retention rate, bDMARDs did diminish disease activity. Therefore, physicians should not hesitate in initiating bDMARDs in LOAS. One of the main strengths of our study is that it was based on real-world 
data of patients with AS, with relatively large sample size and long follow-up period [5-7]. Moreover, nonradiographic axSpA, which has been shown to be different from AS, was excluded [33]. The results of our study could be specific and helpful for patients with LOAS considering initiating bDMARDs. In addition, the National Health Insurance Service in Korea strictly monitors the diagnosis of AS (through the mNY criteria [14]) and the use of bDMARDs for every rheumatic disease. The initiation, continuation, and discontinuation of bDMARDs are carefully observed as physicians check the disease activity in the designated cycle according to the type of bDMARD. These help in drawing accurate conclusions about the efficacy and drug retention rate of bDMARDs in patients with AS.

There are some limitations to this study. Firstly, data from KOBIO did not represent the entirety of patients with AS, and only patients receiving bDMARDs were included. Therefore, there could be a difference in baseline characteristics between this group and patients with AS not receiving bDMARDs. Secondly, the

pharmacokinetics of each bDMARD was not considered. Each drug has its own time of onset for showing effects in the human body. Disease activity scores and treatment response could not demonstrate the potency of each bDMARD at the first follow-up. Thirdly, the choice of bDMARDs was solely dependent on each rheumatologist's preference, without a specific protocol. Fourthly, there was no data on secukinumab in LOAS, therefore, its efficacy and retention rate could not be evaluated. Despite these limitations, data from the KOBIO registry could reflect the real-world and give useful evidence for starting bDMARDs for patients with LOAS.

In conclusion, patients with LOAS had lower bDMARDs efficacy and comparable drug retention rate compared to those with YOAS. There were no differences in the efficacy and drug retention rate of each bDMARD in LOAS. These results could be helpful for patients with LOAS who require bDMARD initiation.

\section{List Of Abbreviations}

AS, Ankylosing spondylitis; axSpA, axial spondyloarthritis; HLA, human leukocyte antigen; ASAS, Assessment of SpondyloArthritis International Society; LOAS, late-onset AS; YOAS, young-onset AS; bDMARDs, biologic disease-modifying antirheumatic drugs; EULAR, European League Against Rheumatism; NSAIDs, non-steroidal anti-inflammatory drugs; KOBIO, Korean College of Rheumatology Biologics and Targeted Therapy; tsDMARDs, targeted synthetic DMARDs; mNY, modified New York; CRP, C-reactive protein; BASDAl, Bath Ankylosing Spondylitis Disease Activity Index; PGA, Patient's Global Assessment; BASFI, Bath Ankylosing Spondylitis Functional Index; ASDAS, Ankylosing Spondylitis Disease Activity Score; ESR, Erythrocyte Sediment Rate; Cll, clinically important improvement; MI, major improvement; $\mathrm{OR}$, odds ratio; $\mathrm{Cl}$, confidence interval; $\mathrm{PS}$, propensity score; $\mathrm{BMI}$, body mass index

\section{Declarations}

\section{Ethics approval and consent to participate}


This study was conducted in accordance with the Declaration of Helsinki ((1964 Declaration of Helsinki and its later amendments). Written informed consent was obtained from each patient. This study was approved by the Institutional Review Board of Konkuk University Medical Center (approval number: 202012-001).

\section{Consent for publication}

Not applicable

\section{Availability of data and materials}

The datasets used and/or analyzed during the current study are available from the corresponding author on reasonable request.

\section{Competing interests}

The authors declare that they have no competing interests relevant to this manuscript.

\section{Funding}

No specific funding was received from any bodies in the public, commercial or not-for-profit sectors to carry out the work described in this article.

\section{Author's contributions}

HKM designed and conceptualized the study and revised the manuscript. SHK carried out the analysis and wrote the manuscript. HRK and SHL reviewed the results. KS and HAK provided the data of KOBIO registry. All authors have read and approved the final manuscript.

\section{Acknowledgements}

Thanks for the KOBIO registry which made data affordable to prepare for journal.

\section{References}

1. Sieper J, Rudwaleit M, Baraliakos X, Brandt J, Braun J, Burgos-Vargas R, Dougados M, Hermann KG, Landewé R, Maksymowych W et al: The Assessment of SpondyloArthritis international Society (ASAS) handbook: a guide to assess spondyloarthritis. Ann Rheum Dis 2009, 68 Suppl 2:ii1-44.

2. Feldtkeller E, Khan MA, van der Heijde D, van der Linden S, Braun J: Age at disease onset and diagnosis delay in HLA-B27 negative vs. positive patients with ankylosing spondylitis. Rheumatol Int 2003, 23(2):61-66.

3. Rudwaleit M, van der Heijde D, Landewé R, Listing J, Akkoc N, Brandt J, Braun J, Chou CT, CollantesEstevez E, Dougados M et al: The development of Assessment of SpondyloArthritis international Society 
classification criteria for axial spondyloarthritis (part II): validation and final selection. Ann Rheum Dis 2009, 68(6):777-783.

4. Toussirot $E$, Wendling $D$ : Late-onset ankylosing spondylitis and related spondylarthropathies: clinical and radiological characteristics and pharmacological treatment options. Drugs Aging 2005, 22(6):451469.

5. Endo Y, Fujikawa K, Koga T, Mizokami A, Mine M, Tsukada T, Uetani M, Kawakami A: Characteristics of late-onset spondyloarthritis in Japan: A retrospective cohort study. Medicine (Baltimore) 2019, 98(7):e14431.

6. Skare TL, Leite N, Bortoluzzo AB, Gonçalves CR, da Silva JA, Ximenes AC, Bértolo MB, Ribeiro SL, Keiserman M, Menin R et al: Effect of age at disease onset in the clinical profile of spondyloarthritis: a study of 1424 Brazilian patients. Clin Exp Rheumatol 2012, 30(3):351-357.

7. Karaarslan A, Yilmaz H, Aycan H, Orman M, Kobak S: Demographic, clinical, and laboratory features of Turkish patients with late onset ankylosing spondylitis. Bosn J Basic Med Sci 2015, 15(3):64-67.

8. Chen HA, Chen CH, Liao HT, Lin YJ, Chen PC, Chen WS, Chien CC, Chou CT: Clinical, functional, and radiographic differences among juvenile-onset, adult-onset, and late-onset ankylosing spondylitis. $J$ Rheumatol 2012, 39(5):1013-1018.

9. Montilla C, Del Pino-Montes J, Collantes-Estevez E, Font P, Zarco P, Mulero J, Gratacós J, Rodríguez C, Juanola $X$, Fernández-Sueiro $\mathrm{JL}$ et al: Clinical features of late-onset ankylosing spondylitis: comparison with early-onset disease. J Rheumatol 2012, 39(5):1008-1012.

10. Toussirot É: Diagnosis and Management of Late-Onset Spondyloarthritis: Implications of Treat-toTarget Recommendations. Drugs Aging 2015, 32(7):515-524.

11. van der Heijde D, Ramiro S, Landewé R, Baraliakos X, Van den Bosch F, Sepriano A, Regel A, Ciurea A, Dagfinrud $\mathrm{H}$, Dougados $\mathrm{M}$ et al: 2016 update of the ASAS-EULAR management recommendations for axial spondyloarthritis. Ann Rheum Dis 2017, 76(6):978-991.

12. Ward MM, Deodhar A, Gensler LS, Dubreuil M, Yu D, Khan MA, Haroon N, Borenstein D, Wang R, Biehl A et al: $\mathbf{2 0 1 9}$ Update of the American College of Rheumatology/Spondylitis Association of America/Spondyloarthritis Research and Treatment Network Recommendations for the Treatment of Ankylosing Spondylitis and Nonradiographic Axial Spondyloarthritis. Arthritis Rheumato/2019, 71(10):1599-1613.

13. Kim SK, Choe JY, Lee SS, Shin K: Body mass index is related with the presence of syndesmophyte in axial spondyloarthritis: Data from the Korean College of Rheumatology BIOlogics (KOBIO) registry. Mod Rheumatol 2017, 27(5):855-861. 
14. van der Linden S, Valkenburg HA, Cats A: Evaluation of diagnostic criteria for ankylosing spondylitis. A proposal for modification of the New York criteria. Arthritis Rheum 1984, 27(4):361-368.

15. Toussirot $\mathrm{E}$ : Late-onset ankylosing spondylitis and spondylarthritis: an update on clinical manifestations, differential diagnosis and pharmacological therapies. Drugs Aging 2010, 27(7):523-531.

16. Machado P, Landewé R, Lie E, Kvien TK, Braun J, Baker D, van der Heijde D: Ankylosing Spondylitis Disease Activity Score (ASDAS): defining cut-off values for disease activity states and improvement scores. Ann Rheum Dis 2011, 70(1):47-53.

17. Anderson JJ, Baron G, van der Heijde D, Felson DT, Dougados M: Ankylosing spondylitis assessment group preliminary definition of short-term improvement in ankylosing spondylitis. Arthritis Rheum 2001, 44(8):1876-1886.

18. Micheroli R, Tellenbach C, Scherer A, Bürki K, Niederman K, Nissen MJ, Zufferey P, Exer P, Möller B, Kyburz $D$ et al: Effectiveness of secukinumab versus an alternative TNF inhibitor in patients with axial spondyloarthritis previously exposed to TNF inhibitors in the Swiss Clinical Quality Management cohort. Ann Rheum Dis 2020, 79(9):1203-1209.

19. Maneiro JR, Souto A, Salgado E, Mera A, Gomez-Reino JJ: Predictors of response to TNF antagonists in patients with ankylosing spondylitis and psoriatic arthritis: systematic review and meta-analysis. $R M D$ Open 2015, 1(1):e000017.

20. Lahaye C, Tatar Z, Dubost JJ, Soubrier M: Overview of biologic treatments in the elderly. Joint Bone Spine 2015, 82(3):154-160.

21. Baraliakos X, van den Berg R, Braun J, van der Heijde D: Update of the literature review on treatment with biologics as a basis for the first update of the ASAS/EULAR management recommendations of ankylosing spondylitis. Rheumatology (Oxford) 2012, 51(8):1378-1387.

22. Baeten D, Baraliakos X, Braun J, Sieper J, Emery P, van der Heijde D, Mclnnes I, van Laar JM, Landewé $\mathrm{R}$, Wordsworth $\mathrm{P}$ et al: Anti-interleukin-17A monoclonal antibody secukinumab in treatment of ankylosing spondylitis: a randomised, double-blind, placebo-controlled trial. Lancet 2013, 382(9906):1705-1713.

23. Baeten D, Sieper J, Braun J, Baraliakos X, Dougados M, Emery P, Deodhar A, Porter B, Martin R, Andersson $\mathrm{M}$ et al: Secukinumab, an Interleukin-17A Inhibitor, in Ankylosing Spondylitis. N Engl J Med 2015, 373(26):2534-2548.

24. Fleischmann R, Baumgartner SW, Weisman MH, Liu T, White B, Peloso P: Long term safety of etanercept in elderly subjects with rheumatic diseases. Ann Rheum Dis 2006, 65(3):379-384.

25. Fleischmann R, lqbal I: Risk: benefit profile of etanercept in elderly patients with rheumatoid arthritis, ankylosing spondylitis or psoriatic arthritis. Drugs Aging 2007, 24(3):239-254. 
26. Chevillotte-Maillard H, Ornetti P, Mistrih R, Sidot C, Dupuis J, Dellas JA, Tavernier C, Maillefert JF: Survival and safety of treatment with infliximab in the elderly population. Rheumatology (Oxford) 2005, 44(5):695-696.

27. Maillard H, Ornetti P, Grimault L, Ramon JF, Ducamp SM, Saidani T, Tavernier C, Maillefert JF: Severe pyogenic infections in patients taking infliximab: a regional cohort study. Joint Bone Spine 2005, 72(4):330-334.

28. Arends S, van der Veer E, Kallenberg CG, Brouwer E, Spoorenberg A: Baseline predictors of response to TNF-a blocking therapy in ankylosing spondylitis. Curr Opin Rheumatol 2012, 24(3):290-298.

29. Rusman T, van Vollenhoven RF, van der Horst-Bruinsma IE: Gender Differences in Axial Spondyloarthritis: Women Are Not So Lucky. Curr Rheumatol Rep 2018, 20(6):35.

30. Arends S, Brouwer E, van der Veer E, Groen H, Leijsma MK, Houtman PM, Th AJTL, Kallenberg CG, Spoorenberg A: Baseline predictors of response and discontinuation of tumor necrosis factor-alpha blocking therapy in ankylosing spondylitis: a prospective longitudinal observational cohort study. Arthritis Res Ther 2011, 13(3):R94.

31. Glintborg B, Ostergaard M, Krogh NS, Dreyer L, Kristensen HL, Hetland ML: Predictors of treatment response and drug continuation in 842 patients with ankylosing spondylitis treated with anti-tumour necrosis factor: results from 8 years' surveillance in the Danish nationwide DANBIO registry. Ann Rheum Dis 2010, 69(11):2002-2008.

32. Kristensen LE, Karlsson JA, Englund M, Petersson IF, Saxne T, Geborek P: Presence of peripheral arthritis and male sex predicting continuation of anti-tumor necrosis factor therapy in ankylosing spondylitis: an observational prospective cohort study from the South Swedish Arthritis Treatment Group Register. Arthritis Care Res (Hoboken) 2010, 62(10):1362-1369.

33. Kiltz U, Baraliakos X, Karakostas P, Igelmann M, Kalthoff L, Klink C, Krause D, Schmitz-Bortz E, Flörecke $\mathrm{M}$, Bollow $\mathrm{M}$ et al: Do patients with non-radiographic axial spondylarthritis differ from patients with ankylosing spondylitis? Arthritis Care Res (Hoboken) 2012, 64(9):1415-1422.

\section{Figures}



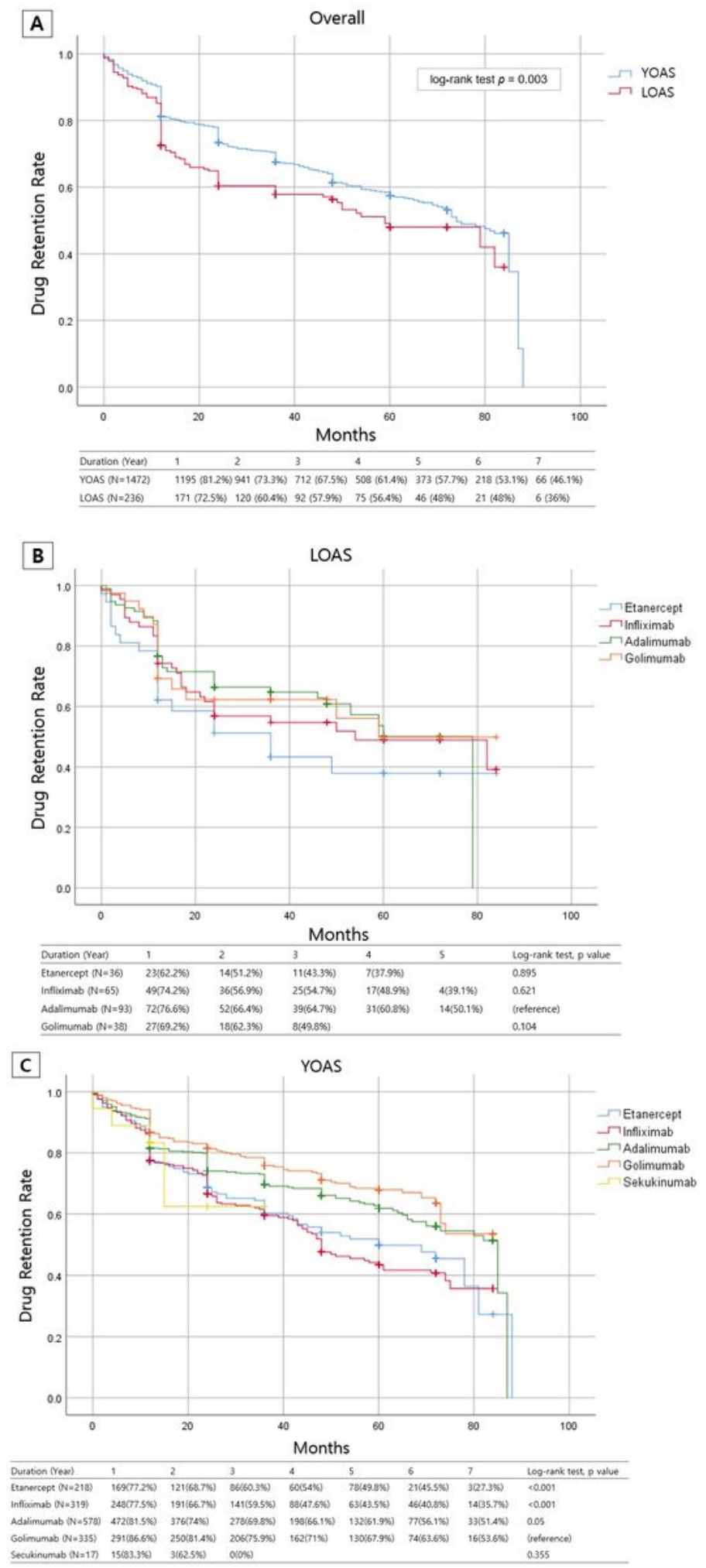

\section{Figure 1}

Drug retention rates of biologic disease modifying antirheumatic drug (bDMARD). (A) Drug retention rate of overall late onset ankylosing spondylitis (LOAS) and young onset ankylosing spondylitis (YOAS). LOAS showed lower drug retention rate than YOAS. Drug retention rates of each bDMARDs in LOAS (B) and YOAS (C). 


\section{Supplementary Files}

This is a list of supplementary files associated with this preprint. Click to download.

- SupplementaryTable.docx 